\title{
Soil Bacteria Confer Plant Salt Tolerance by Tissue-Specific Regulation of the Sodium Transporter HKT1
}

\author{
Huiming Zhang, ${ }^{1}$ Mi-Seong Kim, ${ }^{1}$ Yan Sun, ${ }^{1}$ Scot E. Dowd, ${ }^{2}$ Huazhong Shi, ${ }^{1}$ and Paul W. Paré ${ }^{1}$ \\ ${ }^{1}$ Texas Tech University; Department of Chemistry, Biochemistry and Biology Lubbock 79409, U.S.A.; ${ }^{2}$ United States \\ Department of Agriculture-Agricultural Research Service, Livestock Issues Research Unit; RT 3 Box 214 FM 1294 ; \\ Lubbock, TX 79403, U.S.A.
}

Submitted 4 November 2007. Accepted 6 February 2008.

\begin{abstract}
Elevated sodium $\left(\mathrm{Na}^{+}\right)$decreases plant growth and, thereby, agricultural productivity. The ion transporter high-affinity $\mathrm{K}^{+}$transporter (HKT)1 controls $\mathrm{Na}^{+}$import in roots, yet dysfunction or overexpression of $H K T 1$ fails to increase salt tolerance, raising questions as to HKT1's role in regulating $\mathrm{Na}^{+}$homeostasis. Here, we report that tissuespecific regulation of $H K T 1$ by the soil bacterium Bacillus subtilis GB03 confers salt tolerance in Arabidopsis thaliana. Under salt stress (100 $\mathrm{mM} \mathrm{NaCl})$, GB03 concurrently down- and upregulates $H K T 1$ expression in roots and shoots, respectively, resulting in lower $\mathrm{Na}^{+}$accumulation throughout the plant compared with controls. Consistent with HKT1 participation in GB03-induced salt tolerance, GB03 fails to rescue salt-stressed athkt1 mutants from stunted foliar growth and elevated total $\mathrm{Na}^{+}$whereas saltstressed $\mathrm{Na}^{+}$export mutants sos 3 show GB03-induced salt tolerance with enhanced shoot and root growth as well as reduced total $\mathrm{Na}^{+}$. These results demonstrate that tissuespecific regulation of $\mathrm{HKT1}$ is critical for managing $\mathrm{Na}^{+}$homeostasis in salt-stressed plants, as well as underscore the breadth and sophistication of plant-microbe interactions.
\end{abstract}

Soil salinity is a major constraint to modern agriculture, with approximately $20 \%$ of once-irrigated land worldwide presently salt contaminated (Frommer et al. 1999). For most trees and crop plants that are salt sensitive, elevated $\mathrm{Na}^{+}$imposes toxic effects by perturbing potassium $\left(\mathrm{K}^{+}\right)$-dependent processes, inducing deleterious protein conformations, and causing osmotic stress that causes growth inhibition and, ultimately, cell death (Chinnusamy et al. 2006; Greenway and Munns 1980; Wyn Jones 1981). To avoid accumulating toxic $\mathrm{Na}^{+}$levels in the shoots, plants must take up no more than $3 \%$ of the $\mathrm{Na}^{+}$present in the rhizosphere (Munns et al. 1999). For salt-stressed plants, restricting $\mathrm{Na}^{+}$uptake and shoot $\mathrm{Na}^{+}$accumulation is critical for minimizing salt phytotoxicity.

High-affinity $\mathrm{K}^{+}$transporters (HKT) mediate $\mathrm{Na}^{+}$transport in higher plants, including Arabidopsis, wheat, and rice (Platten et al. 2006). HKT1 originally was sequenced from wheat roots and identified as HKT (Schachtman and Schroeder 1994). Yeast expression of wheat HKT1 revealed that, at physiologically detrimental $\mathrm{Na}^{+}$concentrations, HKT1 switches from an HKT to a low-affinity $\mathrm{Na}^{+}$transporter (Rubio et al. 1995). Studies in heterologous expression systems and in planta have

Corresponding author: P. W. Paré; Telephone: 806-742-3062; Fax: 806742-1289; E-mail: Paul.Pare@ttu.edu established HKT1 as a $\mathrm{Na}^{+}$transporter that controls $\mathrm{Na}^{+}$uptake (Haro et al. 2005; Mäser et al. 2002a; Rubio et al. 1995; Rus et al. 2001, 2004; Schachtman and Schroeder 1994; Sunarpi et al. 2005; Uozumi et al. 2000). In Arabidopsis, HKT1 functions as a negative regulator of $\mathrm{K}^{+}$nutrition rather than as a $\mathrm{K}^{+}$uptake system (Rus et al. 2004), whereas AtHKT1 expressed in Xenopus oomycetes exhibits selective transport of $\mathrm{Na}^{+}$but not $\mathrm{K}^{+}$(Uozumi et al. 2000). In addition to regulation of $\mathrm{Na}^{+}$influx in roots (Haro et al. 2005; Laurie et al. 2002; Rus et al. 2001), HKT1 and other HKT proteins are proposed to function in shoots to retrieve $\mathrm{Na}^{+}$from the xylem, thereby facilitating shootto-root $\mathrm{Na}^{+}$recirculation, as demonstrated in Arabidopsis (Berthomieu et al. 2003; Davenport et al. 2007; Mäser et al. 2002a; Sunarpi et al. 2005), rice (Garciadeblas et al. 2003; Ren et al. 2005), and wheat (Byrt et al. 2007; Huang et al. 2006; James et al. 2006). Being a driver for $\mathrm{Na}^{+}$influx and recirculation, HKT1 has unexpectedly been an elusive target for engineering $\mathrm{Na}^{+}$regulation in plants, because both loss-of-function and overexpression of HKT1 disturb ion status and increase salt sensitivity (Mäser et al. 2002a; Rus et al. 2004).

Plant growth-promoting rhizobacteria (PGPR) are naturally occurring soil microorganisms that colonize roots and stimulate plant growth. Such bacteria have been applied to a wide range of agricultural crops for the purpose of growth enhancement, including increased seed germination, plant weight, harvest yields, and disease resistance (Kloepper et al. 1980, 1991, 1999). Under non-salt-stress conditions, PGPR colonization is proposed to trigger growth by bacterial synthesis of the plant hormones indole-3-acetic acid, cytokinin, and gibberellins, as well as by increased mineral and nitrogen availability in the soil (Glick 1999; Lin et al. 1983; Loper and Schroth 1986; MacDonald et al. 1986; Timmusk et al. 1999). In the absence of physical contact with plant roots, blends of volatile chemicals emitted from specific strains of PGPR trigger growth promotion in Arabidopsis (Paré et al. 2005; Ryu et al. 2003, 2004). Bacillus subtilis GB03, a commercially available soil symbiont, is one such strain that emits a complex blend of volatile components that activates plant growth promotion. A bouquet of over 25 bacterial volatile odors has been identified that trigger differential expression of approximately 600 Arabidopsis transcripts related to cell wall modifications, primary and secondary metabolism, stress responses, hormone regulation, and other expressed proteins (Farag et al. 2006; Ryu et al. 2003; Zhang et al. 2007). In addition, whole-plant $H K T 1$ transcript levels are reduced in plants grown under low $\mathrm{Na}^{+}$conditions, presenting a possible regulatory role of GB03 in increasing salt tolerance (Zhang et al. 2007). In this study, the potential of GB03 to increase plant re- 
sistance to salt stress by regulating HKT1 gene expression is investigated. Here, we monitor plant salt tolerance and tissuespecific HKT1 gene expression with Arabidopsis exposure to GB03 volatiles. Mutant studies allow for assigning an HKT1 role in GB03-triggered plant salt tolerance.

\section{RESULTS}

\section{GB03 induces $H K T 1$-dependent plant salt tolerance.}

With elevated $\mathrm{NaCl}(100 \mathrm{mM})$ in the growth medium, Arabidopsis (Col-0) plants exposed to GB03 volatiles show robust foliar growth (Fig. 1A) compared with water controls. Fourteen days after treatments, GB03-exposed plants clearly exhibit enhanced shoot growth (Fig. 1B) as well as root growth (Fig. 1C) on medium with $100 \mathrm{mM} \mathrm{NaCl}$, demonstrating the capacity of GB03 to confer plant salt tolerance. The abundance of HKT1 transcripts in whole plants grown with $100 \mathrm{mM} \mathrm{NaCl}$ decreases to $48 \% 4$ days postexposure to GB03 (Fig. 2). Interestingly, ubiquitous dysfunction of Arabidopsis HKTl has been shown to cause higher $\mathrm{Na}^{+}$accumulation in shoots and, thereby, foliar $\mathrm{Na}^{+}$hypersensitivity with $100 \mathrm{mM} \mathrm{NaCl}$ (Horie et al. 2006; Mäser et al. 2002a). Although GB03 concomitantly reduces $H K T l$ expression and enhances shoot growth in wild-type (WT) Arabidopsis, hktl mutants exhibited stunted shoot growth under salt stress with or without GB03 present (Fig. 3A and B), indicating that HKT1 is critical for GB03 to trigger tolerance in shoots of salt-stressed plants. Meanwhile, $h k t 1$ mutation results in greater root growth in salt-stressed plants, with the average root mass being $2.1 \mathrm{mg}$ in $h k t l$ (Fig. 3C) compared with $1.1 \mathrm{mg}$ for WT plants (Fig. 1C), which is consistent with the observation that GB03-triggered reduction of $H K T 1$ correlates with greater root growth in salt-stressed plants (Fig. 1C). Combined, these observations suggest that bacterial regulation of $H K T 1$ may not be uniform throughout the plant as in $h k t l$.

\section{Tissue-specific Arabidopsis HKT1 regulation by GB03.}

To characterize GB03 regulation, HKT1 transcripts were monitored tissue specifically. GB03 exposure up- and downregulates $H K T 1$ gene expression in shoots and roots, respectively, within 4 days (Fig. 4A and B). Twenty-four hours of bacteria exposure is sufficient to reduce root $H K T 1$ expression by approximately $50 \%$ compared with control plants, although

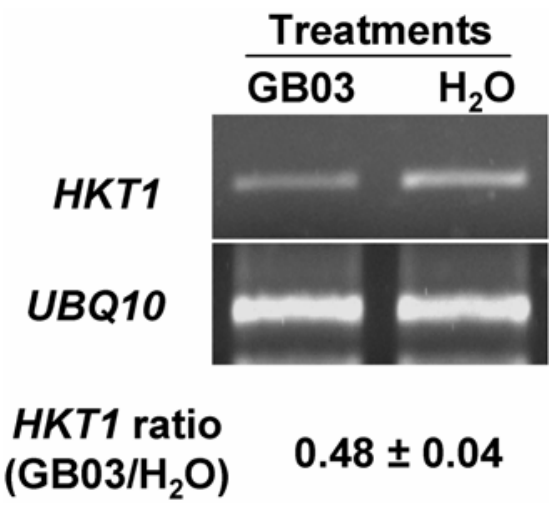

Fig. 2. HKT1 transcript level in salt-stressed plants is decreased by GB03. Plants $(\mathrm{Col}-\mathrm{O})$ were grown in medium with $100 \mathrm{mM} \mathrm{NaCl}$ and harvested 4 days after exposure to GB03 or water control. Quantification of HKT1 expression ratio $\left(\mathrm{GB} 03 / \mathrm{H}_{2} \mathrm{O}\right)$ from reverse-transcriptase polymerase chain reaction results is shown; $U B Q 10$ is employed as an equal loading control $(n=3$, mean \pm standard deviation $)$.
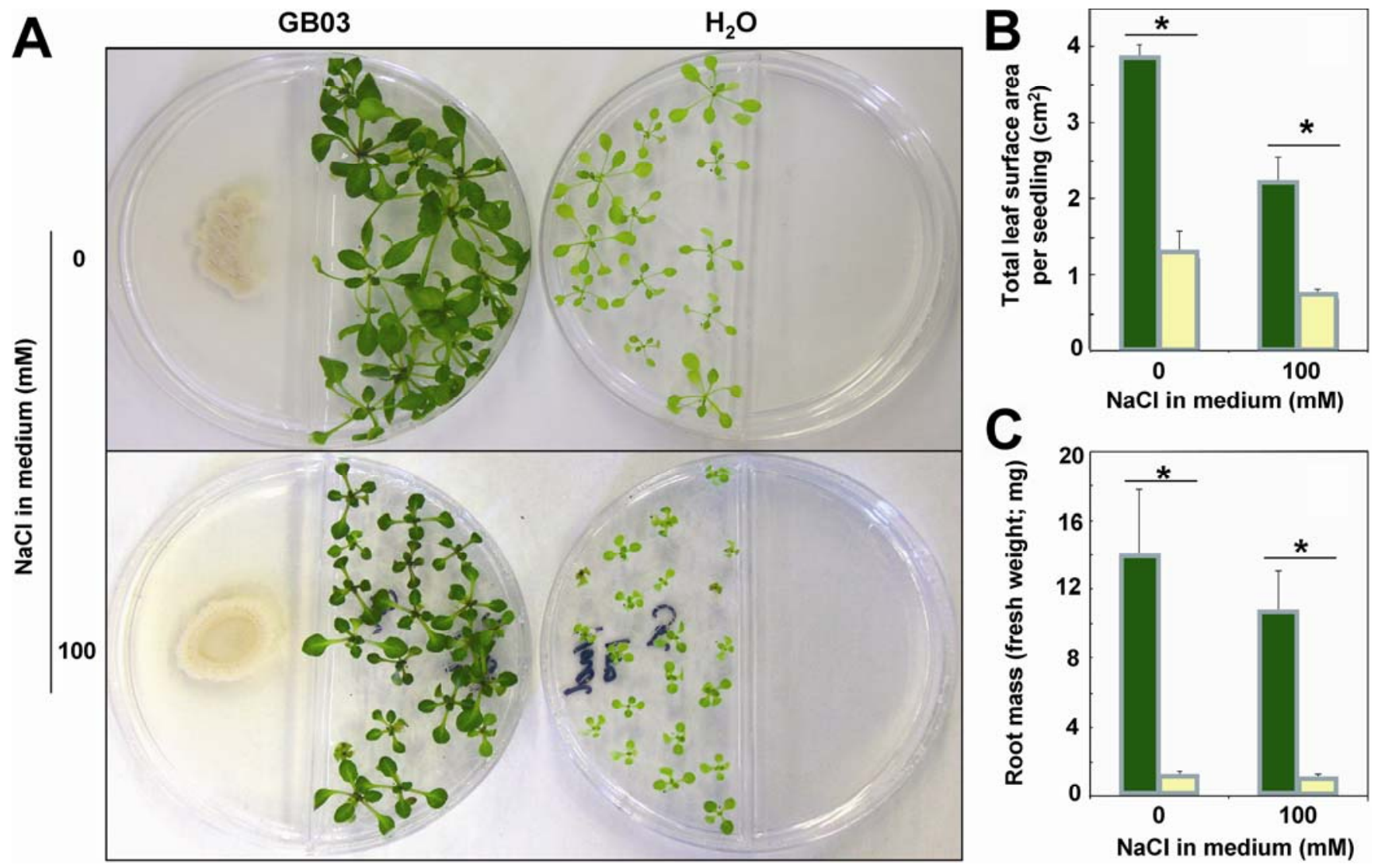

Fig. 1. GB03 confers salt tolerance in Arabidopsis (Col-0). A, Representative images are depicted of plants with exposure to GB03 or water as control for 14 days. GB03 triggers enhancement of B, shoot growth as well as $\mathbf{C}$, root growth. Green and yellow bars represent GB03 and water control treatments, respectively; an asterisk (*) indicates a $P \leq 0.05$ for treated versus controls ( $t$ test; $n \geq 30$, mean \pm standard deviation). 
shoot $H K T 1$ transcript levels were not significantly different in GB03-exposed and control plants at that time. GB03-triggered induction of shoot HKT1 expression shows a bell-shaped trend, with the maximum induction being more than fourfold after 3 days of treatments (Fig. 4A). Meanwhile, up to $70 \%$ reduction in root HKT1 expression of GB03-exposed plants was observed compared with control plants (Fig. 4B). In light of the fact that HKT1 controls $\mathrm{Na}^{+}$uptake in roots as well as shoot-to-root $\mathrm{Na}^{+}$recirculation (Berthomieu et al. 2003; Davenport et al. 2007; Laurie et al. 2002; Mäser et al. 2002a; Rus et al. 2001; Sunarpi et al. 2005), tissue-specific regulation of HKT1 expression by GB03 suggests reduced $\mathrm{Na}^{+}$uptake and enhanced shoot-to-root $\mathrm{Na}^{+}$recirculation (Fig. 4C).

\section{HKT1 mediates GB03-regulated $\mathrm{Na}^{+}$and $\mathrm{K}^{+}$homeostasis with salt stress.}

To test the hypothesis that tissue-specific regulation of $H K T 1$ is necessary and sufficient for GB03-induced plant salt tolerance, $\mathrm{Na}^{+}$accumulation was examined in plants grown with 100 $\mathrm{mM} \mathrm{NaCl}$. Fourteen days postexposure, total $\mathrm{Na}^{+}$accumulation in GB03-exposed plants was $54 \%$ of that in nonexposed plants (Fig. 5A), indicating reduced $\mathrm{Na}^{+}$import, enhanced $\mathrm{Na}^{+}$export, or both. In GB03-exposed roots, $\mathrm{Na}^{+}$reduction followed lower HKTl expression coding for $\mathrm{Na}^{+}$import (Fig. 5A and 4B); whereas, for GB03-exposed shoots, $\mathrm{Na}^{+}$reduction was consistent with enhanced $H K T l$ expression coding for $\mathrm{Na}^{+}$recirculation. In addition, the $h k t l$ mutation abrogated reduction of $\mathrm{Na}^{+}$ accumulation triggered by GB03 exposure in the whole plant as well as tissue specifically (Fig. 5B). Without shoot HKT1 operative $(h k t 1), \mathrm{GB} 03$ failed to reduce shoot $\mathrm{Na}^{+}$levels. Assuming that shoot HKT1 regulates shoot-to-root $\mathrm{Na}^{+}$recirculation,
(Berthomieu et al. 2003; Davenport et al. 2007; Mäser et al. 2002a), the difference in shoot $\mathrm{Na}^{+}$for mutant and WT lines (Fig. 5A and B) provides an approximation of $\mathrm{Na}^{+}$recirculation. However, because significant differences in total $\mathrm{Na}^{+}$between hktl and WT lines with GB03 exposure do exist (80 versus 140 mg per gram of dry weight, respectively), unidentified factors such as reduced uploading of $\mathrm{Na}^{+}$from roots to shoots may overestimate GB03-induced $\mathrm{Na}^{+}$recirculation values.

In addition to reducing $\mathrm{Na}^{+}$levels, GB03 exposure increases total $\mathrm{K}^{+}$content in WT plants (Fig. 5C). Specifically, $\mathrm{K}^{+}$accumulation in roots was increased more than twofold, while $\mathrm{K}^{+}$ level in shoots decreased by approximately $50 \%$ (Fig. 5C). In contrast, no difference of $\mathrm{K}^{+}$level was observed in $h k t 1$ plants with or without GB03 exposure (Fig. 5D). Water-treated hktl mutants exhibited higher $\mathrm{K}^{+}$levels $(74.0 \pm 1.8 \mathrm{mg} / \mathrm{g}$ dry weight) than WT plants $(24.2 \pm 0.5 \mathrm{mg} / \mathrm{g}$ dry weight) (Fig. 5C and D), confirming that HKT1 negatively regulates $\mathrm{K}^{+}$accumulation. The negative role of HKT1 in $\mathrm{K}^{+}$accumulation is supported by the observations that higher $H K T 1$ expression is detected in shoots of GB03-exposed WT plants (Fig. 4A) and accumulate less $\mathrm{K}^{+}$(Fig. 5C), whereas roots have lower HKT1 expression (Fig. 4B) and accumulate more $\mathrm{K}^{+}$(Fig. 5C). GB03 modulation of $\mathrm{Na}^{+}$and $\mathrm{K}^{+}$accumulation in salt-stressed WT plants resulted in an increased $\mathrm{K}^{+} / \mathrm{Na}^{+}$ratio from a whole-plant perspective and, specifically, in roots (Fig. 3E). No $\mathrm{K}^{+} / \mathrm{Na}^{+}$ ratio difference was observed for $h k t 1$ plants with or without GB03 exposure (Fig. 5F).

GB03 induces salt tolerance in the $\mathrm{Na}^{+}$export mutant sos3.

To determine whether $\mathrm{Na}^{+}$export participates in GB03-triggered reduction of plant $\mathrm{Na}^{+}$levels, GB03 effects were moni-
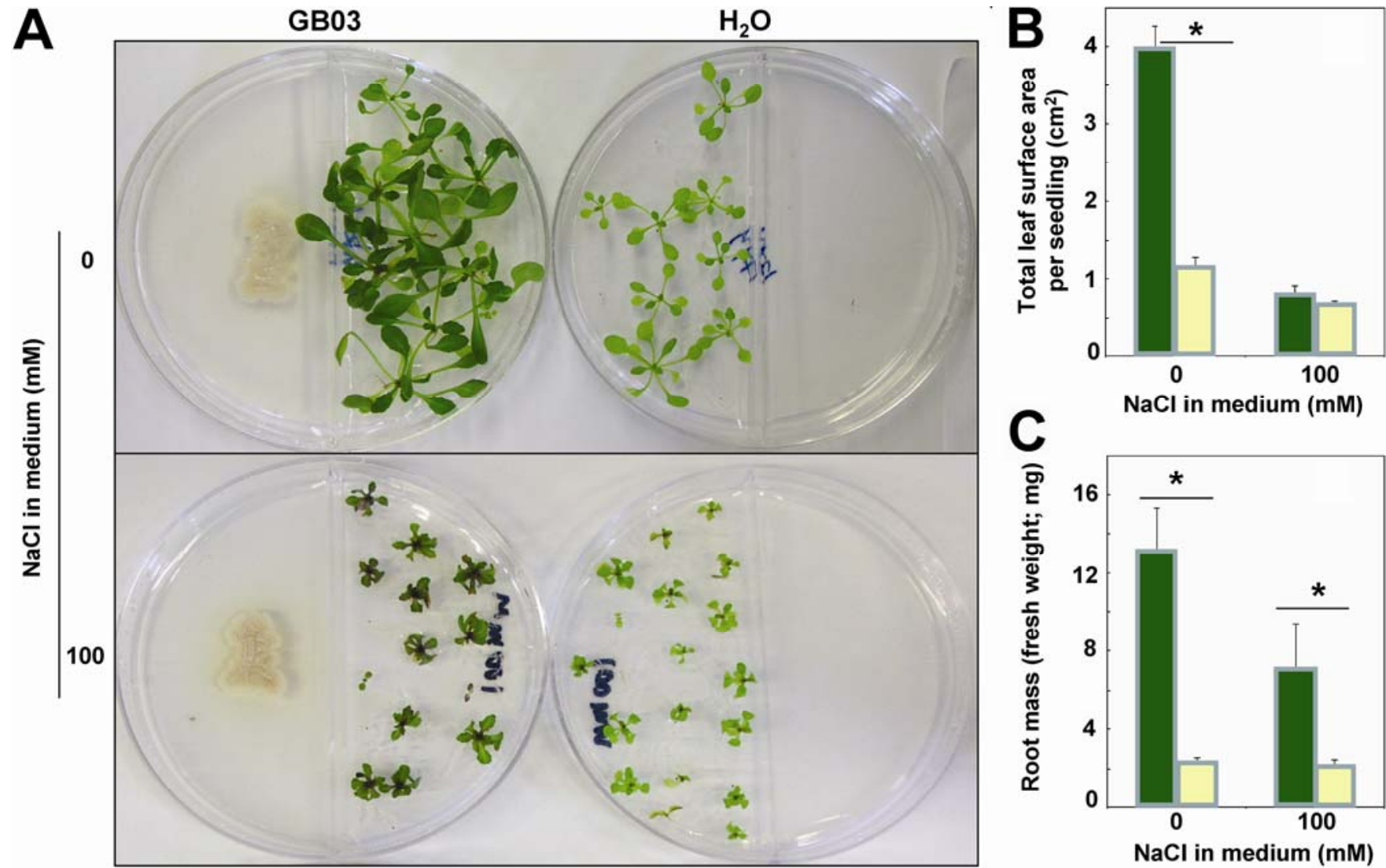

Fig. 3. The hkt1 mutation disrupts GB03-triggered plant salt tolerance. A, Representative images are shown of plants with exposure to GB03 or water controls for 14 days. B, HKT1 is not necessary for GB03-triggered growth promotion in plants without salt stress, whereas $h k t 1$ mutation abolishes plant salt tolerance induced by GB03. C, GB03 enhances root growth in hkt1 mutants. Green and yellow bars represent GB03 and water control treatments, respectively; an asterisk (*) indicates a $P \leq 0.05$ for treated versus controls ( $t$ test; $n \geq 30$, mean \pm standard deviation). 
tored using an Arabidopsis sos3 mutant line that is hypersensitive to $30 \mathrm{mM} \mathrm{NaCl}$ due to disruption in the SOS signaling pathway that regulates $\mathrm{Na}^{+}$efflux (Rus et al. 2001; Zhu 2002). Salt-stressed sos 3 plants concomitantly show less root- and shoot-growth inhibition with GB03 exposure (Fig. 6A through C). Moreover, 14 days postexposure, GB03 decreased total $\mathrm{Na}^{+}$level by $18 \%$ in sos 3 plants grown with $30 \mathrm{mM} \mathrm{NaCl}$ (Fig. 6D), suggesting that $\mathrm{Na}^{+}$accumulation can be reduced by GB03 independent of $\mathrm{Na}^{+}$export activation. Therefore, GB03reduced total $\mathrm{Na}^{+}$accumulation (Fig. 3A) can be attributed, at least in part, to reduced $\mathrm{Na}^{+}$uptake. GB03-triggered decrease of $\mathrm{Na}^{+}$level was not observed in sos 3 roots (Fig. 6D). This may be due to defected $\mathrm{Na}^{+}$export by $\operatorname{sos} 3$ mutation combined with enhanced shoot-to-root $\mathrm{Na}^{+}$recirculation triggered by GB03. $\mathrm{Na}^{+}$hypersensitivity of $\operatorname{sos} 3$ plants correlates with reduced $\mathrm{K}^{+}$accumulation, resulting in root growth inhibition (Rus et al. 2001; Zhu et al. 1998). With GB03 exposure, $\mathrm{K}^{+}$ content in $\operatorname{sos} 3$ roots was increased by more than twofold (Fig. $6 \mathrm{E})$. Thus, increased $\mathrm{K}^{+}$content in $\operatorname{sos} 3$ roots is consistent with the suppression of salt-inhibited root growth.

\section{DISCUSSION}

HKT1 is a focal determinant of $\mathrm{Na}^{+}$homeostasis. Although whole-plant genetic manipulation of $H K T 1$ has been unsuccessful to confer salt tolerance, herein we show that tissuespecific HKT1 gene regulation by the soil bacterium GB03 effectively controls $\mathrm{Na}^{+}$homeostasis in salt-stressed plants. Mutant studies further confirmed the key role of HKT1 tissuespecific regulation in GB03-triggered plant salt tolerance. In- creasing evidence supports the dual role of HKT1 in regulating $\mathrm{Na}^{+}$homeostasis via $\mathrm{Na}^{+}$uptake and recirculation; therefore, observations in this study underscore the importance of tissuespecific investigation in understanding HKT1 activity and function. Such tissue-specific regulation of HKT1 by beneficial bacteria provides an alternative strategy for crop protection against high soil salinity.

Plants in saline environment can protect themselves from $\mathrm{Na}^{+}$toxicity through restricting $\mathrm{Na}^{+}$entry; excluding $\mathrm{Na}^{+}$from root cells; sequestering $\mathrm{Na}^{+}$into vacuoles; or retrieving $\mathrm{Na}^{+}$ from the transpirational xylem stream for recirculation to roots (Chinnusamy et al. 2006). $\mathrm{Na}^{+} / \mathrm{H}^{+}$antiporters in the plasma membrane $(S O S 1)$ and in the tonoplast $(N H X 1)$ control $\mathrm{Na}^{+}$ export and vacuolar $\mathrm{Na}^{+}$sequestration, respectively. Genetic engineering for plant salt tolerance through overexpression of these two genes has been straightforward and successful (Apse et al. 1999; Shi et al. 2003). In contrast, although HKT1 regulates $\mathrm{Na}^{+}$uptake as well as shoot-to-root $\mathrm{Na}^{+}$recirculation, ubiquitous alteration of $H K T 1$ gene expression has been unfavorable for conferring plant salt tolerance. Disruption of $H K T 1$ in Arabidopsis leads to shoot $\mathrm{Na}^{+}$hypersensitivity due to higher $\mathrm{Na}^{+}$accumulation in shoots (Mäser et al. 2002a; Rus et al. 2004); whereas overexpression of $H K T 1$ causes $\mathrm{Na}^{+}$-specific salt hypersensitivity and decreases $\mathrm{K}^{+} / \mathrm{Na}^{+}$ratios in roots due to reduced $\mathrm{K}^{+}$accumulation (Rus et al. 2004). In addition, dysfunction of $H K T 1$ has been reported to partially rescue $\mathrm{Na}^{+}$ inhibition of root growth in $\operatorname{sos} 3$ background (Rus et al. 2001); however, $h k t 1$ sos 3 double mutants are still shoot salt sensitive, similar to the hktl mutant, as a result of increased shoot $\mathrm{Na}^{+}$ level (Horie et al. 2006). Because sos3 and hktl exhibit salt
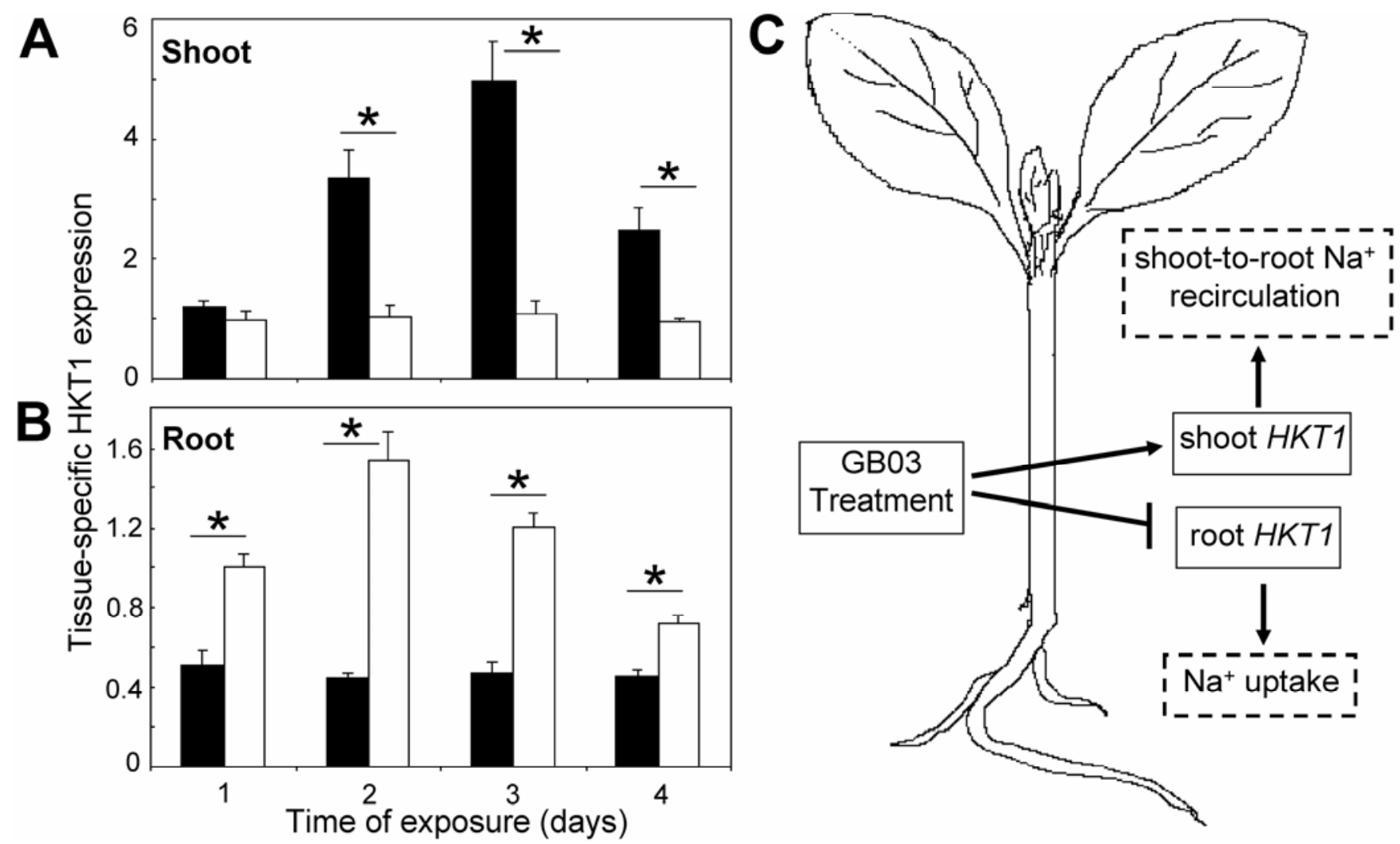

Fig. 4. HKT1 tissue-specific expression in salt-stressed $\mathrm{Col}-0$ is differentially regulated with GB03 exposure. Two-day-old wild-type seedlings are GB03 exposed and $\mathbf{A}$, shoot as well as $\mathbf{B}$, root $H K T 1$ is monitored over a 4-day period. The values detected by quantitative real-time polymerase chain reaction are relative to water-treated values observed on day 1 ; black and white bars represent GB03 and controls, respectively, with an asterisk (*) indicating a $P \leq 0.05$ for treated versus controls ( $t$ test; $n=3$, mean \pm standard deviation). C, Model of $H K T 1$-dependent $\mathrm{Na}^{+}$regulation by GB03. HKT1 controls Na ${ }^{+}$import in roots (Laurie et al. 2002; Rus et al. 2001) as well as $\mathrm{Na}^{+}$transport from xylem vessels to phloem for shoot-to-root $\mathrm{Na}^{+}$recirculation (Berthomieu et al. 2003; Davenport et al. 2007; Mäser et al. 2002a; Sunarpi et al. 2005). Therefore, GB03-triggered reduction of root $H K T 1$ limits Na ${ }^{+}$entry into plants, whereas GB03-induction of shoot $H K T 1$ facilitates $\mathrm{Na}^{+}$retrieval from shoot to root. 
stress at different salt doses (30 and $100 \mathrm{mM} \mathrm{NaCl}$, respectively) (Horie et al. 2006; Mäser et al. 2002a; Rus et al. 2001), individual salt-stress conditions were necessary for each mutant line to assay for GB03-induced salt tolerance and avoid salt toxicity.

Given the dual function of HKT1 in regulating $\mathrm{Na}^{+}$homeostasis, with $\mathrm{Na}^{+}$import into roots (Laurie et al. 2002; Rus et al. 2001) and $\mathrm{Na}^{+}$recirculation from the shoots (Berthomieu et al. 2003; Davenport et al. 2007; Mäser et al. 2002a; Sunarpi et al. 2005), tissue-specific regulation of HKT1 expression appears to be critical for GB03-conferred salt tolerance in plants (Fig. 4C). Reduction of root $H K T 1$ limits $\mathrm{Na}^{+}$entry into plants, while induction of shoot $H K T 1$ facilitates $\mathrm{Na}^{+}$retrieval from shoot to root, thereby managing $\mathrm{Na}^{+}$equilibrium and conferring salt tolerance. Consistent with the upregulation of shoot $H K T 1$ expression that indicates enhanced shoot-to-root $\mathrm{Na}^{+}$recirculation, GB03-exposed plants accumulate less $\mathrm{Na}^{+}$in shoots compared with control plants. Meanwhile, the downregulation of root $H K T 1$ correlates with reduced root as well as whole-plant $\mathrm{Na}^{+}$levels. Therefore, tissue-specific regulation is here shown to be critical for plant salt tolerance conferred through manipulation of $H K T 1$ gene expression.

Bacterial regulation reduces whole-plant $\mathrm{Na}^{+}$accumulation as evidenced by lower $\mathrm{Na}^{+}$levels in both shoots and roots. Such reduction in $\mathrm{Na}^{+}$accumulation is unlikely to be dependent on activation of $\mathrm{Na}^{+}$efflux, because disruption of the SOS signaling pathway that regulate $\mathrm{Na}^{+}$efflux does not abolish the GB03-increased salt tolerance (Fig. 6). The key role of HKT1 in GB03-induced resistance to salt stress is further confirmed by hktl mutant plants, which show higher shoot $\mathrm{Na}^{+}$level as well as $\mathrm{Na}^{+}$hypersensitivity in shoots than WT plants. GB03 is unable to reduce shoot $\mathrm{Na}^{+}$accumulation or to release the saltstressed phenotype in shoots of $h k t l$ plants, indicating that GB03-induced salt tolerance requires functional HKT1.

Toxic levels of $\mathrm{Na}^{+}$perturb $\mathrm{K}^{+}$homeostasis that is essential for plant metabolism (Elumalai et al. 2002; Maathuis and Sanders 1996; Rigas et al. 2001). Functional expression in heterologous systems revealed that wheat HKT1 mediates $\mathrm{Na}^{+}-$ coupled $\mathrm{K}^{+}$transport, whereas Arabidopsis HKT1 transports only $\mathrm{Na}^{+}$(Rubio et al. 1995; Uozumi et al. 2000). The different
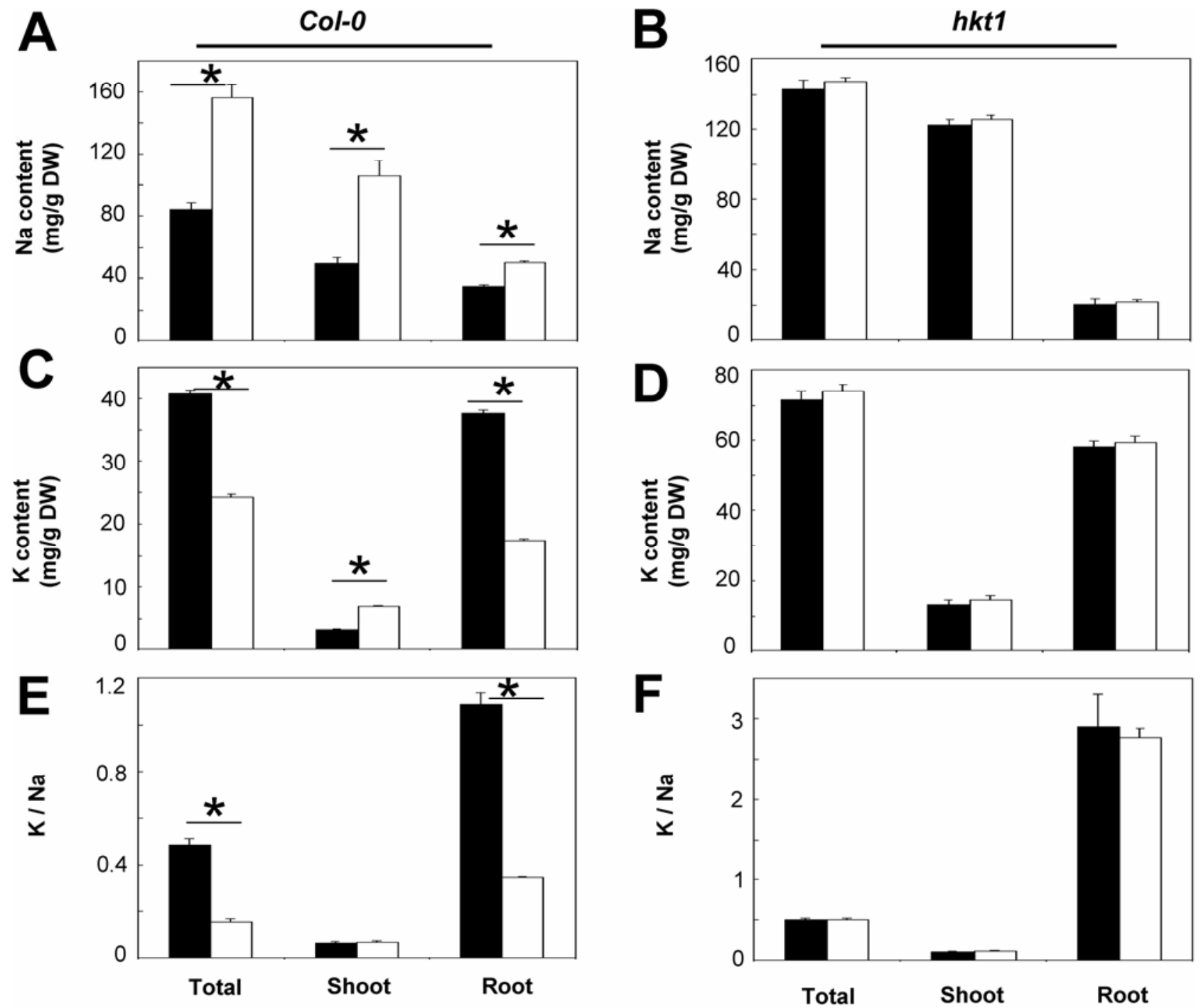

Fig. 5. GB03 decreases $\mathrm{Na}^{+}$accumulation and increases $\mathrm{K}^{+}$nutrient status under salt stress and functioning HKT1. A, Na ${ }^{+}$level is lower in 16-day-old wildtype shoots and roots with GB03 exposure for 14 days whereas $\mathbf{B}, H K T 1$ dysfunction abolishes the GB03-triggered reduction of foliar Na ${ }^{+}$accumulation and reduces root $\mathrm{Na}^{+}$level compared with the wild type. Correlated with GB03-induced up- and downregulation of $H K T 1$ in shoots and roots, respectively, $\mathbf{C}$, GB03-exposed plants accumulate less and more $\mathrm{K}^{+}$in shoots and roots, respectively, indicating a negative role of $H K T 1$ in $\mathrm{K}^{+}$uptake in the wild type. $\mathbf{D}$, GB03 does not affect $\mathrm{K}^{+}$accumulation in $h k t 1$ mutants. E, As a result of regulating $\mathrm{Na}^{+}$and $\mathrm{K}^{+}$accumulation tissue specifically, GB03 increases $\mathrm{K}^{+} / \mathrm{Na}^{+}$ ratios in roots but not in shoots of $\mathrm{Col}-0 . \mathbf{F}, \mathrm{K}^{+} / \mathrm{Na}^{+}$ratios in $h k t 1$ plants are not affected by GB03 exposure. Black and white bars represent GB03 and water controls, respectively, with an asterisk (*) indicating $P \leq 0.05$ for treated versus controls $(t$ test; $n=4$, mean \pm standard deviation). 
$\mathrm{K}^{+}$permeability in these HKT1 proteins is attributed to a critical glycine residue which resides in the $\mathrm{K}^{+}$channel selectivity filter GYG motif (Mäser et al. 2002b). Nevertheless, genetic evidence has been shown that HKT1 negatively regulates $\mathrm{K}^{+}$ nutrition in Arabidopsis (Rus et al. 2004), despite the fact that Arabidopsis HKT1 selectively transports $\mathrm{Na}^{+}$but not $\mathrm{K}^{+}$ (Uozumi et al. 2000). Our results support the negative role of HKT1 in $\mathrm{K}^{+}$nutrition (Fig. 5C and D). With GB03 exposure, plants accumulate more $\mathrm{K}^{+}$in roots where $H K T 1$ expression is downregulated. On the other hand, GB03-exposed plants accumulate more $H K T 1$ transcripts as well as less $\mathrm{K}^{+}$in shoots. Therefore, regulation of $H K T 1$ expression by GB03 modulates not only $\mathrm{Na}^{+}$but also $\mathrm{K}^{+}$homeostasis tissue specifically. Compared with the control plants, GB03-exposed plants show a higher $\mathrm{K}^{+} / \mathrm{Na}^{+}$ratio in roots whereas no difference is observed in shoot $\mathrm{K}^{+} / \mathrm{Na}^{+}$ratios. As a result, GB03-exposed plants have greater capacity for $\mathrm{K}^{+} / \mathrm{Na}^{+}$-selective accumulation from a whole-plant perspective, in medium supplemented with 100 $\mathrm{mM} \mathrm{NaCl}$.

The plant symbiont GB03 displays an as yet unidentified volatile signal or signals to achieve tissue-specific HKT1 regulation. In addition, GB03-generated volatile signals that induce salt tolerance are produced whether the bacteria are grown under low or elevated $\mathrm{NaCl}(0,100$, and $150 \mathrm{mM})$ in the media (data not shown). HKT-type transporters have been found in several plant species, including rice and wheat, yet regulatory mechanisms of gene expression remains unknown (Fairbairn et al. 2000; Garciadeblas et al. 2003; Horie et al. 2001; Ren et al. 2005; Rubio et al. 1995). Future analyses of volatile chemicals from GB03 that trigger HKT1 regulation and regulatory elements of $H K T 1$ expression in planta are likely to reveal molecular mechanisms for the tissue-specific regulation of $H K T 1$.

\section{MATERIALS AND METHODS}

\section{Plant materials and treatments.}

Arabidopsis thaliana seed were surface sterilized and then planted on one side of specialized plastic petri dishes (100 by
$15 \mathrm{~mm}$ ) that contained a center partition (I plates; Fisher Scientific, Pittsburgh, U.S.A.); both sides contained half-strength Murashige and Skoog (MS) solid media with $0.8 \%$ (wt/vol) agar, $1.5 \%$ (wt/vol) sucrose, and $\mathrm{NaCl}$. Half-strength MS media was prepared according to Murashige and Skoog (1962). Before being placed in the growth room, seed were vernalized for 2 days at $4{ }^{\circ} \mathrm{C}$ with an absence of light. The growth room was set to a cycle of $16 \mathrm{~h}$ of light and $8 \mathrm{~h}$ of darkness under metal halide and high-pressure sodium lamps with a total light intensity of $200 \mu \mathrm{mol} \mathrm{m} \mathrm{m}^{-2} \mathrm{~s}^{-1}$, a temperature of $21 \pm 4^{\circ} \mathrm{C}$, and a relative humidity of $40 \pm 10 \%$.

One day before plant experiments, bacterial strains were streaked onto tryptic soy agar (TSA) plates and incubated at $28^{\circ} \mathrm{C}$ in the absence of light for $24 \mathrm{~h}$. PGPR cells were harvested from TSA plates in double-distilled water (DDW) to yield $10^{9}$ $\mathrm{CFU} \mathrm{ml} \mathrm{m}^{-1}$, as determined by optical density and serial dilutions with plate counts. Two-day-old Arabidopsis seedlings then were inoculated with $20 \mu \mathrm{l}$ of bacterial suspension culture or DDW applied drop wise to the nonplant side of the petri dish.

\section{Quantification of leaf surface and root growth.}

For leaf area quantification, seedlings were photographed 14 days after the treatments using an Olympus C-4000 camera (Olympus American Inc., Melville, NY, U.S.A.). Images were imported into Adobe Photoshop 5.5 and leaf surface area measurements were determined by using an available histogram function; pixel areas were calibrated based the total petri dish area. For root growth measurement, sos3 seed were germinated and grown in half-strength MS media without supplement of $\mathrm{NaCl}$. Four-day-old seedlings were transferred to vertical I-plates containing 0 or $30 \mathrm{mM} \mathrm{NaCl}$ in the media for plant growth. Root growth measurement was performed 5 days after transfer.

\section{$\mathrm{Na}^{+}$and $\mathrm{K}^{+}$content measurement.}

Plants with 14 days of GB03 or water exposure were harvested, rinsed with deionized water, and dried at $65^{\circ} \mathrm{C}$ for 2 days. Dried tissue was extracted with $100 \% \mathrm{HNO}_{3}$ overnight,
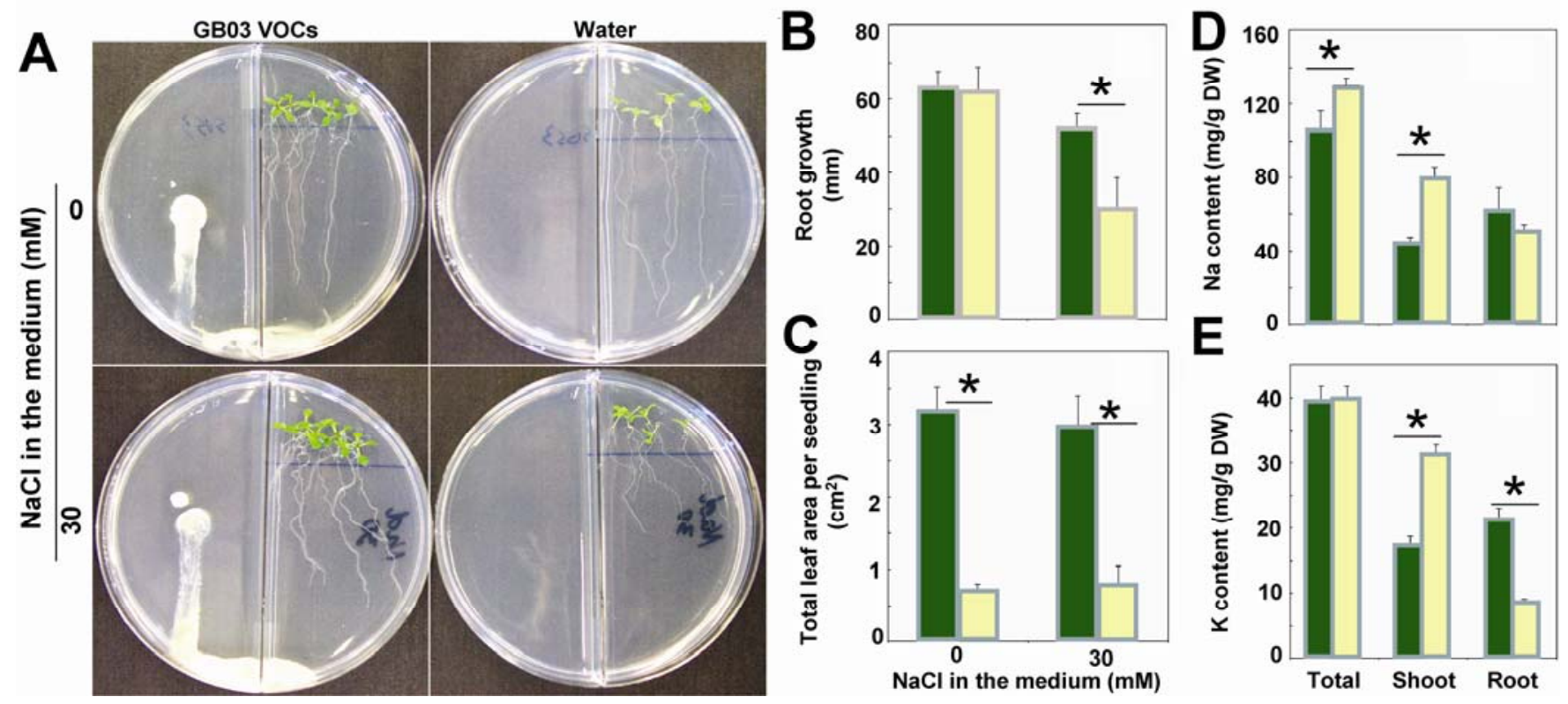

Fig. 6. GB03 suppresses sodium hypersensitivity for sos3. GB03 attenuates root growth inhibition with elevated NaCl by A, visual inspection and B, root growth quantification $(n=30)$. C, GB03-exposed sos3 plants also show improved shoot growth with $30 \mathrm{mM}$ NaCl $(n=36)$. Seed of sos 3 were germinated and grown in half-strength Murashige and Skoog media without $\mathrm{NaCl}$ for 4 days and compared 5 days after transfer to specified salt media. D, GB03 reduces $\mathrm{Na}^{+}$accumulation in $\operatorname{sos} 3$ plants and, specifically, in shoots. E, $\mathrm{K}^{+}$levels in shoots and roots of sos 3 plants were decreased and increased by GB03, respectively. Measurements for $\mathrm{Na}^{+}, \mathrm{K}^{+}$, and total leaf area were performed 14 days post-treatment. Green and yellow bars represent GB03 and water control treatments, respectively; an asterisk (*) indicates $P \leq 0.05$ for treated versus controls ( $t$ test; mean \pm standard deviation). 
followed by incubation at 90 to $100^{\circ} \mathrm{C}$ for $1 \mathrm{~h}$. Then, $2.5 \%$ $\mathrm{HNO}_{3}$ was added to the digested samples. Aqueous $\mathrm{Na}^{+}$was determined by atomic absorption spectrophotometry (Model 6300; Shimadzu Scientific Instruments, Columbia, MD, U.S.A.).

\section{RNA extraction and \\ reverse-transcriptase polymerase chain reaction.}

RNA was extracted following Qiagen RNeasy protocol (Qiagen, Valencia, CA, U.S.A.).

Reverse transcriptase polymerase chain reaction. Wholeplant RNA was extracted 4 days after $\mathrm{GB} 03$ or $\mathrm{H}_{2} \mathrm{O}$ exposure. First-strand cDNA was synthesized from $5 \mu \mathrm{g}$ of total RNA using MuMLV-RT (Fisher Scientific, Houston). The following primers were used $\left(5^{\prime}\right.$ to $\left.3^{\prime}\right)$ : UBQ10, CGATTACTCTTGAGG TGGAG and AGACCAAGTGAAGTGTGGAC; and HKT1, ATCGCTGTGACGTTGAGACT and ATCAGAAACCCTAGC ACCGT. Agarose gel electrophoresis images were taken by Kodak Gel Logic 100 Imaging System (Fisher Scientific, Houston) and quantified by using Image $\mathrm{J} 1.33 \mathrm{u}$.

Quantitative real-time polymerase chain reaction. RNA from shoots and roots were extracted separately at 1,2, 3, and 4 days postexposure. Reverse transcription of all the RNA samples was carried out using random hexamers. ABI TaqMan reverse transcription reagent kit (Applied Biosystems, Foster City, CA, U.S.A.) was used for first-strand synthesis in $50-\mu 1$ reactions (containing $1 \mu \mathrm{g}$ of total RNA) at $37^{\circ} \mathrm{C}$ for $60 \mathrm{~min}$. The expression levels of the HKT1 gene in different Arabidopsis tissues were detected by the ABI PRISM 7000 sequence detection system. The primers were designed by using the PrimerQuest program (Integrated DNA Technology, Coralville, IA, U.S.A.). 18S rRNA primers were used for RNA normalization. SYBR Green PCR master mix (Applied Biosystems) was used for 50 - $\mu$ l polymerase chain reaction (PCR) reactions as follow: $50^{\circ} \mathrm{C}$ for $2 \mathrm{~min}, 95^{\circ} \mathrm{C}$ for $10 \mathrm{~min}$, and 40 cycles of $95^{\circ} \mathrm{C}$ for $15 \mathrm{~s}$ and $60^{\circ} \mathrm{C}$ for $60 \mathrm{~s}$. Each sample was assayed three times. The relative expression levels of all the samples were calculated and analyzed (User Bulletin no. 2, ABI PRISM 7700 sequence detection system). The threshold cycle (Ct value) of the target genes and 18S RNA in different samples were obtained after quantitative real-time PCR reaction. In brief, the normalizer $18 \mathrm{~S}$ RNA Ct value was subtracted from the gene of interest $\mathrm{Ct}$ (target gene) to produce the $\mathrm{dCt}$ value of the sample. The $\mathrm{dCt}$ value of the calibrator (the sample with the highest $\mathrm{dCt}$ value) was subtracted from every other sample to produce the ddCt value. Two to the $-\mathrm{ddCt}$ power $\left(2^{-\mathrm{ddCt}}\right)$ was taken for every sample as the relative expression levels.

\section{ACKNOWLEDGMENTS}

Financial support was provided by the Welch (Grant D-1478) and ACSFrasch Foundations for Chemical Research.

\section{LITERATURE CITED}

Apse, M. P., Aharon, G. S., Snedden, W. A., and Blumwald, E. 1999. Salt tolerance conferred by overexpression of a vacuolar $\mathrm{Na}^{+} / \mathrm{H}^{+}$antiport in Arabidopsis. Science 285:1256-1258.

Berthomieu, P., Conejero, G., Nublat, A., Brackenbury, W. J., Lambert, C., Savio, C., Uozumi, N., Oiki, S., Yamada, K., Cellier, F., Gosti, F., Simonneau, T., Essah, P. A., Tester, M., Very, A. A., Sentenac, H., and Casse, F. 2003. Functional analysis of AtHKT1 in Arabidopsis shows that $\mathrm{Na}^{+}$recirculation by the phloem is crucial for salt tolerance. EMBO (Eur. Mol. Biol. Organ.) J. 22:2004-2014.

Byrt, C. S., Platten, J. D., Spielmeyer, W., James, R. A., Lagudah, E. S., Dennis, E. S., Tester, M., and Munns, R. 2007. HKT1;5-like cation transporters linked to $\mathrm{Na}^{+}$exclusion loci in wheat, Nax2 and Kna1. Plant Physiol. 143:1918-1928.
Chinnusamy, V., Zhu, J., and Zhu, J. K. 2006. Salt stress signaling and mechanisms of plant salt tolerance. Genet. Eng. 27:141-177.

Davenport, R. J., Munoz-Mayor, A., Jha, D., Essah, P. A., Rus, A., and Tester, M. 2007. The $\mathrm{Na}^{+}$transporter AtHKT1 controls retrieval of $\mathrm{Na}^{+}$ from the xylem in Arabidopsis. Plant Cell Environ. 30:497-507.

Elumalai, R. P., Nagpal, P., and Reed, J. W. 2002. A mutation in the Arabidopsis KT2/KUP2 potassium transporter gene affects shoot cell expansion. Plant Cell 14:119-131.

Fairbairn, D. J., Liu, W., Schachtman, D. P., Gomez-Gallego, S., Day, S. R., and Teasdale, R. D. 2000. Characterisation of two distinct HKT1like potassium transporters from Eucalyptus camaldulensis. Plant Mol Biol. 43:515-525

Farag, M. A., Ryu, C. M., Sumner, L. W., and Pare, P. W. 2006. GC-MS SPME profiling of rhizobacterial volatiles reveals prospective inducers of growth promotion and induced systemic resistance in plants. Phytochemistry 67:2262-2268.

Frommer, W. B., Ludewig, U., and Rentsch, D. 1999. Taking transgenic plants with a pinch of salt. Science 285:1222-1223.

Garciadeblas, B., Senn, M. E., Banuelos, M. A., Rodriguez-Navarro, A. 2003. Sodium transport and HKT transporters: the rice model. Plant J. 34:788-801.

Glick, B. R. 1999. Biochemical and Genetic Mechanisms Used by Plant Growth Promoting Bacteria. B. R. Glick, C. N. Patten, G. Holguin, and D. M. Penrose, eds. Imperial College Press, London.

Greenway, H., and Munns, R. 1980. Mechanisms of salt tolerance in nonhalophytes. Annu. Rev. Plant Physiol. 31:149-190.

Haro, R., Bañuelos, M. A., Senn, M. E., Barrero-Gil, J., and RodríguezNavarro, A. 2005. HKT1 mediates sodium uniport in roots. Pitfalls in the expression of HKT1 in yeast. Plant Physiol. 139:1495-1506.

Horie, T., Yoshida, K., Nakayama, H., Yamada, K., Oiki, S., and Shinmyo, A. 2001. Two types of HKT transporters with different properties of $\mathrm{Na}^{+}$and $\mathrm{K}^{+}$transport in Oryza sativa. Plant J. 27:129-138.

Horie, T., Horie, R., Chan, W. Y., Leung, H. Y., and Schroeder, J. I. 2006 Calcium regulation of sodium hypersensitivities of $\operatorname{sos} 3$ and athkt $1 \mathrm{mu}-$ tants. Plant Cell Physiol. 47:622-633.

Huang, S., Spielmeyer, W., Lagudah, E. S., James, R. A., Platten, J. D., Dennis, E. S., and Munns, R. 2006. A sodium transporter (HKT7) is a candidate for Nax1, a gene for salt tolerance in durum wheat. Plant Physiol. 142:1718-1727.

James, R. A., Davenport, R. J., and Munns, R. 2006. Physiological characterisation of two genes for $\mathrm{Na}^{+}$exclusion in durum wheat: Naxl and Nax2. Plant Physiol. 142:1537-1547.

Kloepper, J. W., Leong, J., Teintze, M., and Schroth, M. N. 1980. Enhanced plant growth by. siderophores produced by plant growth promoting rhizobacteria. Nature 286:885-886.

Kloepper, J. W., Zablotowicz, R. M, Tipping, E. M., and Lifshitz, R. 1991. Pages 315-326 in: The Rhizosphere and Plant Growth. K. L. Keister and P. B. Cregan, eds. Kluwer, Dordrecht, The Netherlands.

Kloepper, J. W., Rodriguez-Kabana, R., Zehnder, G. W., Murphy, J., Sikora, E., and Fernandez, C. 1999. Plant root-bacterial interactions in biological control of soilborne diseases and potential extension to systemic and foliar diseases. Aust. J. Plant Pathol. 28:27-33.

Laurie, S., Feeney K. A., Maathuis, F. J., Heard, P. J., Brown, S. J., and Leigh, R. A. 2002. A role for HKT1 in sodium uptake by wheat roots. Plant J. 32:139-149.

Lin, W., Okon, Y., and Hardy, R. W. F. 1983. Enhanced mineral uptake by Zea mays and sorghum bicolor roots inoculated with Azospirillum brasilense. Appl. Environ. Microbiol. 45:1775-1779.

Loper, J. E., and Schroth, M. N. 1986. Influence of bacterial sources of indole-3-acetic acid on root elongation of sugar beet. Phytopathology 76:386-389.

Maathuis, F. J. M., and Sanders, D. 1996. Mechanisms of potassium absorption by higher plant roots. Physiol. Plant. 96:158-168.

MacDonald, E. M. S., Powell, G. K., Regier, D. A., Glass, N. L., Roberto, F., Kosuge, T., and Morris, R. O. 1986. Secretion of zwatin, Ribosylzeatin, and ribosyl-1"'-methylzeatin by Pseudomonas savastanoi, plasmid-coded cytokinin biosynthesis. Plant Physiol. 82:742-747.

Mäser, P., Eckelman, B., Vaidyanathan, R., Horie, T., Fairbairn, D. J., Kubo, M., Yamagami, M., Yamaguchi, K., Nishimura, M., Uozumi, N., Robertson, W., Sussman, M. R., and Schroeder, J. I. 2002a. Altered shoot/root $\mathrm{Na}^{+}$distribution and bifurcating salt sensitivity in Arabidopsis by genetic disruption of the $\mathrm{Na}^{+}$transporter AtHKT1. FEBS (Fed. Eur. Biochem. Soc.) Lett. 531:157-161.

Mäser, P., Hosoo, Y., Goshima, S., Horie, T., Eckelman, B., Yamada, K., Yoshida, K., Bakker, E. P., Shinmyo, A., Oiki, S., Schroeder, J. I., and Uozumi, N. 2002b. Glycine residues in potassium channel-like selectivity filters determine potassium selectivity in four-loop-per-subunit HKT transporters from plants. Proc. Natl. Acad. Sci. U.S.A. 99:64286433

Paré, P. W., Farag, M. A., Krishnamachari, V., Zhang, H., Ryu, C. M., and 
Kloepper, J. W. 2005. Elicitors and priming agents initiate plant defense responses. Photosynth. Res. 85:149-159.

Platten, J. D., Cotsaftis, O., Berthomieu, P., Bohnert, H., Davenport, R. J., Fairbairn, D. J., Horie, T., Leigh, R. A., Lin, H. X., and Luan, S. 2006. Nomenclature for HKT transporters, key determinants of plant salinity tolerance. Trends Plant Sci. 11:372-374.

Ren, Z. H., Gao, J. P., Li, L. G., Cai, X. L., Huang, W., Chao, D. Y., Zhu, M. Z., Wang, Z. Y., Luan, S., and Lin, H. X. 2005. A rice quantitative trait locus for salt tolerance encodes a sodium transporter. Nat. Genet. 37:1141-1146.

Rigas, S., Debrosses, G., Haralampidis, K., Vicente-Agullo, F., Feldmann, K. A., Grabov, A., Dolan, L., and Hatzopoulos, P. 2001. TRH1 encodes a potassium transporter required for tip growth in Arabidopsis root hairs. Plant Cell. 13:139-151.

Rubio, F., Gassmann, W., and Schroeder, J. I. 1995. Sodium-driven potassium uptake by the plant potassium transporter HKT1 and mutations conferring salt tolerance. Science 270:1660-1663.

Rus, A., Yokoi, S., Sharkhuu, A., Reddy, M., Lee, B. H., Matsumoto, T. K., Koiwa, H., Zhu, J. K., Bressan, R. A., and Hasegawa, P. M. 2001. AtHKT1 is a salt tolerance determinant that controls $\mathrm{Na}^{+}$entry into plant roots. Proc. Natl. Acad. Sci. U.S.A. 98:14150-14155.

Rus, A., Lee, B. H., Munoz-Mayor, A., Sharkhuu, A., Miura, K., Zhu, J. K., Bressan R. A., and Hasegawa P. M. 2004. AtHKT1 facilitates $\mathrm{Na}^{+}$ homeostasis and $\mathrm{K}^{+}$nutrition in planta. Plant Physiol. 136:2500-2511.

Ryu, C. M., Farag, M. A., Hu, C. H., Reddy, M. S., Wei, H. X., Paré, P. W., and Kloepper, J. W. 2003. Bacterial volatiles promote growth in Arabidopsis. Proc. Natl. Acad. Sci. U.S.A. 100:4927-4932.

Ryu, C. M., Farag, M. A., Hu, C. H., Reddy, M. S., Kloepper, J. W., and Paré, P. W. 2004. Bacterial volatiles induce systemic resistance in Arabidopsis. Plant Physiol. 134:1017-1026.

Schachtman, D. P., and Schroeder, J. I. 1994. Structure and transport mechanism of a high-affinity potassium transporter from higher plants.
Nature 370:655-658

Shi, H., Lee, B. H., Wu, S. J., and Zhu, J. K. 2003. Overexpression of a plasma membrane $\mathrm{Na}^{+} / \mathrm{H}^{+}$antiporter gene improves salt tolerance in Arabidopsis thaliana. Nat. Biotechnol. 21:81-85.

Sunarpi, Horie, T., Motoda, J., Kubo, M., Yang, H., Yoda, K., Horie, R., Chan, W. Y., Leung, H. Y., Hattori, K., Konomi, M., Osumi, M., Yamagami, M., Schroeder, J. I., and Uozumi, N. 2005. Enhanced salt tolerance mediated by AtHKT1 transporter-induced Na unloading from xylem vessels to xylem parenchyma cells. Plant J. 44:928-938.

Timmusk, S., Nicander, B., Granhall, U., and Tillberg, E. 1999. Cytokinin production by Paenibacillus polymyxa. Soil Biol. Biochem. 31:18471852.

Uozumi, N., Kim, E. J., Rubio, F., Yamaguchi, T., Muto, S., Tsuboi, A., Bakker, E. P., Nakamura, T., and Schroeder, J. I. 2000. The Arabidopsis HKT1 gene homolog mediates inward $\mathrm{Na}^{+}$currents in Xenopus laevis oomycetes and $\mathrm{Na}(+)$ uptake in Saccharomyces cerevisiae. Plant Physiol. 122:1249-1259.

Wyn Jones, R. G. 1981. Salt tolerance. Pages 271-292 in: Physiological Processes Limiting Plant Productivity. C B Johnson, ed. Butterworth, London.

Zhang, H., Kim, M. S., Krishnamachari, V., Payton, P., Sun, Y., Grimson, M., Farag, M. A., Ryu, C. M., Allen, R., Melo, I. S., and Paré, P. W. 2007. Rhizobacterial volatile emissions regulate auxin homeostasis and cell expansion in Arabidopsis. Planta 226:839-851.

Zhu, J. K. 2002. Salt and drought stress signal transduction in plants. Annu. Rev. Plant Biol. 53:247-273.

\section{AUTHOR-RECOMMENDED INTERNET RESOURCE}

United States National Institute of Health ImageJ website: rsb.info.nih.gov/ij/ 